\title{
Intranasal versus Intraperitoneal Delivery of Human Umbilical Cord Tissue-Derived Cultured Mesenchymal Stromal Cells in a Murine Model of Neonatal Lung Injury
}

Liansheng Liu, ${ }^{*}$ Quanfu Mao, ${ }^{* \dagger}$ Sharon Chu, ${ }^{\dagger \dagger}$ Marwan Mounayar, ${ }^{\ddagger}$ Reza Abdi, ${ }^{\ddagger}$ William Fodor, ${ }^{\S}$ James F. Padbury, ${ }^{\mathbb{T}\|\|}$ and Monique E. De Paepe ${ }^{* \dagger}$

From the Departments of Pathology* and Pediatrics, ${ }^{\uparrow}$ Women and Infants Hospital, and the Departments of Pathology and Laboratory Medicine ${ }^{\dagger}$ and Pediatrics," Alpert Medical School of Brown University, Providence, Rhode Island; the Transplantation Research Center, ${ }^{\ddagger}$ Brigham and Women’s Hospital, Harvard Medical School, Boston, Massachusetts; and The Cell Therapy Group, ${ }^{\S}$ Madison, Connecticut

Accepted for publication August 5, 2014.

Address correspondence to Monique E. De Paepe, M.D., Department of Pathology, Women and Infants Hospital, 101 Dudley St., Providence, RI 02905. E-mail: mdepaepe@ wihri.org.

\begin{abstract}
Clinical trials investigating mesenchymal stromal cell (MSC) therapy for bronchopulmonary dysplasia have been initiated; however, the optimal delivery route and functional effects of MSC therapy in newborns remain incompletely established. We studied the morphologic and functional effects of intranasal versus i.p. MSC administration in a rodent model of neonatal lung injury. Cultured human cord tissue MSCs $\left(0.1,0.5\right.$, or $1 \times 10^{6}$ cell per pup) were given intranasally or i.p. to newborn severe combined immunodeficiency-beige mice exposed to $90 \% \mathrm{O}_{2}$ from birth; sham controls received an equal volume of phosphate-buffered saline. Lung mechanics, engraftment, lung growth, and alveolarization were evaluated 8 weeks after transplantation. High-dose i.p. MSC administration to newborn mice exposed to $90 \% \mathrm{O}_{2}$ resulted in the restoration of normal lung compliance, elastance, and pressurevolume loops (tissue recoil). Histologically, high-dose i.p. MSC administration was associated with alveolar septal widening, suggestive of interstitial matrix modification. Intranasal MSC or lower-dose i.p. administration had no significant effects on lung function or alveolar remodeling. Pulmonary engraftment was rare in all the groups. These findings suggest that high-dose systemic administration of human cultured MSCs can restore normal compliance in neonatally injured lungs, possibly by paracrine modulation of the interstitial matrix. Intranasal delivery had no obvious pulmonary effects. (Am J Pathol 2014, 184: 3344-3358; http://dx.doi.org/10.1016/j.ajpath.2014.08.010)
\end{abstract}

The incidence of premature delivery in the United States is currently $11 \%$ to $12 \%$ (National Center for Health Statistics, final natality data; retrieved from March of Dimes, http:// www.marchofdimes.com/peristats, last accessed May 5, 2014). Although programmatic efforts at reducing late preterm births have shown regional and national success, the incidence of extremely low-birth-weight infants has remained unchanged. Improved survival has resulted in an increased number of infants at risk for complications of prematurity. Premature infants with structurally immature lungs born between 23 and 28 weeks' gestation are at risk for bronchopulmonary dysplasia (BPD), or chronic lung disease of the preterm newborn, a complex condition associated with high perinatal morbidity and mortality. ${ }^{1-3}$ Despite increased use of exogenous surfactant and antenatal corticosteroids, improved ventilatory strategies, and changes in neonatal intensive care, the proportion of surviving infants with BPD remained unchanged between 1995 and $2006 .{ }^{4}$ An estimated $30 \%$ of very low-birthweight infants $(<1500 \mathrm{~g})$ will develop BPD and are predisposed to its long-term complications, including asthma, emphysema, and poor neurodevelopmental outcome. ${ }^{5,6}$ The risk is even higher at younger gestational ages. The main

Supported in part by a research grant from ViaCord, a Perkin Elmer company (M.E.D.P.).

Disclosures: Viacord/Perkin-Elmer (a cord blood banking company) has not had any influence on the content of the paper. M.E.D.P. has patent applications pending involving the use of stem cells (including MSCs) as therapy for neonatal lung injury. W.F. has received consulting fees from Perkin-Elmer. 
pathologic hallmark of BPD is an arrest of alveolar development, characterized by large, simplified distal airspaces and dysmorphic microvasculature. ${ }^{7-9}$

During the past decade, numerous studies have examined the role of stem cell therapy as an alternative or complementary approach for the treatment of chronic lung disease of the newborn (reviewed in several studies ${ }^{10-12}$ ). Several stem cell types have been tested in experimental models of neonatal lung injury, including mesenchymal stem/stromal cells (MSCs), ${ }^{13-15}$ endothelial progenitor cells or similar myeloid angiogenic progenitor cells, ${ }^{16}$ and CD34-positive hematopoietic progenitor cells ${ }^{17,18}$ (reviewed by Borghesi et $\mathrm{al}^{19}$ ). Based, in large part, on their reported preclinical and clinical success in various adult lung injury paradigms ${ }^{20-26}$ (reviewed by Weiss ${ }^{10}$ ), experimental attention has focused mainly on MSCs as the most promising candidate cell type for pulmonary regenerative therapy in neonatal lung injury. Attractive properties of MSCs in this context include their capacity to specifically home to injured tissue and to exert immunomodulatory activities with secretion of antiinflammatory factors (eg, interferon- $\gamma$, IL-10, vascular endothelial growth factor, and hepatocyte growth factor), ${ }^{20,24,25,27,28}$ angiogenic factors, ${ }^{20}$ and anti-apoptotic factors. $^{29}$ These properties are thought to promote an optimal milieu for repair and regeneration of the injured tissue. Exogenously administered MSCs are believed to exert their effects by cell contact-dependent and paracrine mechanisms involving secretion of specific mediators and transfer of cellular materials, such as proteins, nucleic acids, and cellular organelles (including mitochondria), to host cells via microvesicles ${ }^{30,31}$ (reviewed by Fung and Thebaud ${ }^{32}$ ).

Preclinical studies have demonstrated that intratracheal, i.p., or i.v. administration of bone marrow- or cord blood-derived MSCs can improve alveolar, airway, and vascular structure; improve lung function; attenuate inflammation; decrease fibrosis; ameliorate right heart function; and/or improve exercise capacity in hyperoxia-based neonatal rodent models of BPD. ${ }^{13-15,33,34}$ As in adult models, the beneficial actions of MSCs are believed to be mediated through paracrine mechanisms and immunomodulatory effects rather than through cell engraftment. ${ }^{35,36}$ Umbilical cord blood or tissue (including Wharton substance) may represent an attractive tissue source of MSCs for pulmonary regenerative therapy in newborns. Human umbilical cord (blood or tissue) stem cells can be collected at no risk to the donor, have low immunoreactivity, and have low inherent pathogen transmission. Cord stem cells are especially attractive for the treatment of neonatal diseases because, ideally, the infant's own cord-derived stem cells may be used as an autologous transplant, thus limiting the risk of infection or rejection.

The demonstrated efficiency of human umbilical cord-derived MSCs in preclinical models of neonatal lung injury/BPD has culminated in recent phase 1 clinical trials (reviewed by Antunes et $\mathrm{al}^{37}$ ). Currently, six clinical trials of MSC therapy for BPD have been registered with ClinicalTrials.gov (NCT01297205, NCT01632475, NCT01828957,
NCT02023788, NCT01897987, and NCT01207869, http:// clinicaltrials.gov, last accessed September 12, 2014). Five trials based in South Korea are using or have used Pneumostem MSCs (Medipost, Seoul, Republic of Korea), a human umbilical cord blood MSC preparation developed commercially for the purpose of cell therapy in premature infants with BPD. The results of the first completed study from the Republic of Korea, which was an open-label, single-center, phase 1 clinical study to evaluate the safety and efficacy of Pneumostem MSCs for BPD treatment, were recently published. ${ }^{38}$ In this study, intratracheal MSC transplantation (10 or $20 \times 10^{6}$ cells $/ \mathrm{kg}$ ) was reported to be safe and associated with a significant reduction in various cytokines, including IL-6, IL-8, and transforming growth factor $\beta 1$, in tracheal aspirates on posttransplantation day $7 .^{38}$ One clinical trial from Taiwan describing the use of umbilical cord MSCs for severe BPD is registered with ClinicalTrials.gov (NCT01207869, http://clinicaltrials.gov/show/NCT01207869, last accessed September 12, 2014). The status of this latter study is unknown. All six clinical trials registered involve the delivery of MSCs via intratracheal administration at doses ranging from 3 to $20 \times 10^{6} / \mathrm{kg}$ body weight.

The recent expansion of MSC therapy for neonatal lung diseases from preclinical studies to the clinical arena has introduced a sense of urgency to gain a better understanding of the characteristics, limitations, and benefits of this approach. Several important unresolved issues and knowledge gaps remain, including the optimal delivery route (intrapulmonary versus i.v./systemic), the importance of dose effects, the exact mechanisms of action, the importance of timing of administration, and the long-term effects. ${ }^{19}$ The aim of this study was to perform a systematic, comparative analysis of the dose-dependent effects of intranasal (i.n.)/ intrapulmonary versus (i.p.)/systemic MSC delivery. We carefully examined the functional effects of stem cells on long-term lung mechanics, histologic features, and structure. As a source of MSCs, we used human umbilical cord tissue-derived cultured MSCs. Hyperoxic exposure of newborn mice was used to induce early neonatal lung injury. As described by us and others, ${ }^{39-41}$ moderate to severe hyperoxia during the neonatal period provides a faithful replication of the early acute injury and subsequent alveolar simplification typical of preterm infants with BPD. Deeper insight into the characteristics of MSC therapy in neonatal lung diseases may contribute to evidence-based translation of preclinical experience to a much-needed clinical application.

\section{Materials and Methods}

\section{Isolation, Culture, and Characterization of Cord MSCs}

Human cultured umbilical cord tissue-derived MSCs (tissue cord MSCs, further described as MSCs) were used in all the experiments. Umbilical cord tissue was procured from uncomplicated full-term deliveries at The Christ Hospital (Cincinnati, OH) according to protocols approved by the 
hospital's Institutional Review Board and were sent to the Viacord Processing Lab (Cincinnati, OH). On receipt, the cord was cleaned with a chlorhexadine wipe and then was placed into a sterile cup with $10 \mathrm{~mL}$ of antibiotic solution $(25 \mu \mathrm{g} / \mathrm{mL}$ gentamicin, $100 \mathrm{IU} / \mathrm{mL}$ penicillin, $100 \mu \mathrm{g} / \mathrm{mL}$ streptomycin, and $0.25 \mu \mathrm{g} / \mathrm{mL}$ amphotericin B; all from Lonza Group AG, Basel, Switzerland). After rinses with sterile phosphate-buffered saline (PBS), the cord tissue underwent overnight digestion in collagenase (Collagenase NB 6, GMP grade, $0.75 \mathrm{mg} / \mathrm{mL}$; SERVA Electrophoresis $\mathrm{GmbH}$, Heidelberg, Germany) with antibiotics in a calcium chloride-buffered digestion solution $\left(37^{\circ} \mathrm{C}\right)$. The homogenate was centrifuged to pellet the cell suspension, washed several times, and resuspended in dimethyl sulfoxide freezing media.

Frozen cell aliquots were thawed at $37^{\circ} \mathrm{C}$ and resuspended in culture media (Dulbecco's modified Eagle's medium supplemented with $20 \%$ fetal bovine serum (both from STEMCELL Technologies Inc., Vancouver, BC, Canada), $1 \%$ penicillin/streptomycin, and $1 \%$ L-glutamine (Lonza Group AG). Cells were cultured on collagen-coated plates $\left(37^{\circ} \mathrm{C}, 5 \% \mathrm{CO}_{2}\right)$; medium was replaced every 3 to 4 days. On reaching $70 \%$ to $80 \%$ confluence, MSCs were trypsinized $(0.25 \%$ Trypsin-EDTA; Life Technologies, Carlsbad, CA) to a new passage.

Cultured MSCs at passages 4 to 10 were used in all the experiments. The cells were surface stained using a panel of flow cytometry anti-human antibodies against CD73, CD90, CD105, CD34, CD45, CD14, HLA-ABC, CD49c, CD49e, HLA-DR (BD Biosciences-BD Pharmingen, San Jose, CA), CD49d, and CD49f (eBioscience Inc., San Diego, CA) and were analyzed by flow cytometry. The MSC line selected for this study expressed the mesenchymal stem cell markers CD73, CD90, and CD105. In addition, the cells also expressed HLA class I and various cell adhesion markers (CD49c, CD49d, CD49e, and CD49f). The cells were negative for hematopoietic cell surface antigens CD34, CD45, CD14, CD19, and HLA-DR (HLA class II, not shown). These molecular characteristics conform to the consensus criteria for defining (human) MSCs established by the International Society for Cellular Therapy. ${ }^{42}$

\section{Animal Husbandry, Hyperoxia Exposure, and Cell Administration}

Six-week-old timed pregnant severe combined immunodeficiency-beige mice (Fox Chase SCID beige, T- and B-cell deficient, natural killer cell impaired; Charles River Laboratories, Wilmington, MA) were maintained under pathogen-free conditions. Newborn mice were exposed to room air or hyperoxia $\left(90 \% \mathrm{O}_{2}\right)$ from birth until postnatal day 7 (day of birth is postnatal day 1). For hyperoxia exposure, mice were placed in an airtight Plexiglas chamber. Oxygen concentrations were continuously monitored and controlled with a ProOx 110 in-line oxygen analyzer and controller system (BioSpherix, Redfield, NY). Nursing dams were rotated daily between air- and oxygen-exposed litters to minimize maternal oxygen toxicity.

On postnatal day 5, corresponding to a time point of intense acute lung injury and active tissue remodeling, the pups were randomly assigned to MSC administration by the i.n. or i.p. route. For i.n. inoculation, $20 \mu \mathrm{L}$ of cell suspension containing $0.1,0.5$, or $1 \times 10^{6}$ cells was placed over the nasal orifices, as previously described,$^{40}$ thus ensuring aspiration of stem cells into the lungs. For i.p. delivery, a $25-\mu \mathrm{L}$ Hamilton syringe (Hamilton Co., Reno, NV) with a 26-gauge needle was used for injection of the cell suspension $(0.1,0.5$, or $1 \times 10^{6}$ cells in $20 \mu \mathrm{L}$ of PBS) into the left lower quadrant. The injection was preceded by aspiration to ensure proper localization of the needle. Hyperoxia-exposed sham controls received equal volumes of vehicle buffer (PBS). The i.n. and i.p. deliveries were well tolerated by the normoxic and hyperoxia-exposed pups. The animals were sacrificed 48 hours or 8 weeks after transplantation. All the animal experiments were approved by the institutional animal care and use committee at Lifespan Health System's Rhode Island Hospital and were conducted in accordance with institutional guidelines for the care and use of laboratory animals.

\section{Analysis of Lung Mechanics}

Invasive lung function testing was performed 8 weeks after transplantation by the forced oscillation technique in anesthetized, nonparalyzed, tracheotomized animals with intact chest wall. ${ }^{43}$ Mice were deeply anesthetized with an i.p. injection of $140 \mathrm{mg} / \mathrm{kg}$ of ketamine and $14 \mathrm{mg} / \mathrm{kg}$ of xylazine to eliminate all spontaneous breathing under anesthesia. Body weights were recorded at the start of the procedure. The tracheal cannula was connected to a flexiVent computer-controlled small animal ventilator (SCIREQ Scientific Respiratory Equipment Inc., Montreal, QC, Canada). The mice were ventilated with a tidal volume of $10 \mathrm{~mL} / \mathrm{kg}$ at an average breathing frequency of 150 breaths/min and a positive end-expiratory pressure of $3 \mathrm{~cm} \mathrm{H}_{2} \mathrm{O}$ to prevent alveolar collapse. Lung function parameters were calculated by fitting pressure and volume data to the singlecompartment and constant-phase models. ${ }^{44}$ We measured resistance, compliance, and elastance of the entire respiratory system (airways, lungs, and chest wall) using the Snapshot-150 v7.0 perturbation. Newtonian resistance (a measure of central airway resistance), tissue damping, and tissue elastance were measured using the subsequent Quickprime-3 v7.0 forced oscillation perturbation. Tissue hysteresivity was calculated from tissue damping and tissue elastance values. Finally, maximal pressure-volume (PV) loops were generated between 30 and $-30 \mathrm{~cm} \mathrm{H}_{2} \mathrm{O}$ pressure ( $\mathrm{PVr}-\mathrm{P}=\mathrm{PV}$ ramp pressure regulated) to obtain maximal vital (total) lung capacity, inspiratory capacity from zero pressure, form of deflating PV loop, quasi-static compliance and elastance, and hysteresis (area between the inflating and deflating parts of the PV loop). All the maneuvers and perturbations were performed until at least three 
reproducible measurements were recorded. A coefficient of determination of 0.95 was the lower limit for acceptance of a measurement. For each parameter and each animal, the average of at least three measurements was calculated. The individuals performing the lung function studies (L.L., Q.M., S.C.) and those analyzing the data (Q.M., M.E.D.P.) were blinded with respect to the experimental group of the animals. All the data were collected using flexiWare software version 7.0 (SCIREQ Scientific Respiratory Equipment Inc.) and analyzed offline using Excel 2010 software (Microsoft Corp., Redmond, WA).

\section{Tissue Processing and Bronchoalveolar Lavage}

After lung function testing, the animals were euthanized by sectioning of diaphragm and abdominal vessels. Bronchoalveolar lavage was performed by repetitive tracheal instillation and aspiration of $0.7 \mathrm{~mL}$ of sterile saline $(0.9 \%$ $\mathrm{NaCl})$ until diffuse and complete expansion of the parenchyma was observed. The recovered fluid was pooled. Cells were spun onto microscope slides (1500 rpm, 5 minutes) (Shandon Cytospin 4 cytocentrifuge; Thermo Scientific, Waltham, MA), air-dried, and Giemsa-Wright stained for differential cell counts of macrophages, eosinophils, neutrophils, and lymphocytes. Some slides were Perls stained for detection of iron pigment.

After lavage, the lungs were formalin fixed by standardized tracheal instillation at a constant pressure of $20 \mathrm{~cm} \mathrm{H}_{2} \mathrm{O}$. All the lungs were inflated equally on the same apparatus. Immediately after inflation, the trachea was ligated and the lungs were immersed in formalin for overnight fixation. Selected organs (liver, kidneys, spleen, and heart) were resected and immersion fixed in formalin. To examine the distribution of transplanted cells, selected animals were studied 48 hours after cell administration. In these animals, all abdominal organs and tissues were removed and immersion fixed en bloc. After overnight fixation, the tissues were dehydrated in graded ethanol solutions, embedded in paraffin, and stained with hematoxylin and eosin.

\section{Analysis of Cell Fate and Engraftment}

The presence and localization of MSCs after i.n. or i.p. administration was monitored by taking advantage of the species mismatch between the human cord blood-derived MSCs and their murine host. Systemic and pulmonary distribution of MSCs was tracked by antivimentin immunohistochemical analysis using a specific anti-human vimentin antibody (N1521; Dako, Glostrup, Denmark). This antibody does not recognize the mouse antigen. Antibody binding was detected by the streptavidin-biotin immunoperoxidase method. In addition, the presence of MSCs or their progeny was studied by fluorescent in situ hybridization (FISH) analysis using human-specific alu probes (PR-1001-01; BioGenex, San Ramon, CA), as previously described. ${ }^{17}$ The proliferative activity of engrafted cord blood-derived cells was assessed by combining human alu-FISH analysis with anti-Ki-67 immunohistochemical analysis, as previously described.$^{17}$ In addition to standard epifluorescence microscopy, the sections were viewed by confocal microscopy. Slice or three-dimensional volume reconstruction and projections were generated to ascertain the veracity of colocalization phenomena, as previously described. ${ }^{17,18,40}$

\section{Histomorphometric Analysis of Lung Growth and Alveolar Remodeling}

Morphometric assessment of the growth of peripheral airexchanging lung parenchyma and the contribution of the various lung compartments (airspace versus parenchyma) to the total lung volume was performed using stereologic volumetric techniques, as previously described. ${ }^{45,46}$ The inflated lung volume was determined according to the Archimedes principle. ${ }^{47}$ The areal density of air-exchanging parenchyma $\left[\mathrm{A}_{\mathrm{A}}(\mathrm{ae} / \mathrm{lu})\right]$ was determined by point counting based on computer-assisted image analysis. The total volume of air-exchanging parenchyma $[\mathrm{V}(\mathrm{ae})]$ was calculated by multiplying $\mathrm{A}_{\mathrm{A}}(\mathrm{ae} / \mathrm{lu})$ by inflated lung volume. Alveolarization was quantified by computer-assisted histomorphometric analysis of mean cord length and mean septal wall thickness, as previously described. ${ }^{48}$ All the morphometric assessments were made on coded slides by a single observer (M.E.D.P.) who was unaware of the experimental condition of the animal analyzed.

\section{Data Analysis}

Values are expressed as means \pm SD or SEM. Statistical analyses were performed using standard one-way analysis of variance with the Dunnett multiple comparison test (GraphPad Prism 6 software; GraphPad Software Inc., San Diego, CA). The significance level was set at $P<0.05$.

\section{Results}

Effects of MSC Administration to Hyperoxic Newborn Mice on Somatic Growth, Lung Growth, and Alveolar Remodeling

Newborn mice were exposed to $90 \% \mathrm{O}_{2}$ from birth until postnatal day 7, treated with MSCs (i.n. or i.p.) on postnatal day 5 , and sacrificed 8 weeks after transplantation. The long-term effects of neonatal hyperoxia exposure on somatic and lung growth were determined by comparative analysis of PBS-treated normoxic and hyperoxic controls (Tables 1 and 2).

Hyperoxia during the first neonatal week (late saccular to early alveolar stage of development) had a prolonged adverse effect on somatic growth, resulting in $23 \%$ and $14 \%$ reductions in body weight in in the i.n. and i.p. PBS-treated control groups, respectively. As expected, histopathologic examination of the lungs of hyperoxia-exposed control 
Table 1 Biometry and Lung Morphometry Parameters ( $90 \% \mathrm{O}_{2}$ Experiment) for I.N. Administration of MSCs

\begin{tabular}{|c|c|c|c|c|c|}
\hline \multirow[b]{2}{*}{ Parameter } & \multirow{2}{*}{$\frac{\text { Normoxia }}{\text { PBS }(n=22)}$} & \multicolumn{4}{|l|}{ Hyperoxia } \\
\hline & & PBS $(n=10)$ & MSC low $(n=7)$ & MSC medium $(n=6)$ & MSC high $(n=7)$ \\
\hline $\mathrm{BW}(\mathrm{g})$ & $21.15 \pm 3.38$ & $16.20 \pm 2.58^{* * *}$ & $17.61 \pm 1.49$ & $17.12 \pm 2.52$ & $16.61 \pm 2.78^{*}$ \\
\hline Heart weight (mg) & $160 \pm 30$ & $129 \pm 23$ & $146 \pm 16$ & $138 \pm 35$ & $135 \pm 29$ \\
\hline Heart weight/BW (\%) & $0.75 \pm 0.08$ & $0.79 \pm 0.06$ & $0.83 \pm 0.07$ & $0.80 \pm 0.11$ & $0.81 \pm 0.09$ \\
\hline $\mathrm{V}(\mathrm{lu})(\mu \mathrm{L})$ & $482 \pm 65$ & $424 \pm 82$ & $438 \pm 75$ & $451 \pm 52$ & $433 \pm 69$ \\
\hline $\mathrm{V}(\mathrm{ae})(\mu \mathrm{L})$ & $168 \pm 11$ & $127 \pm 28^{* * *}$ & $144 \pm 33$ & $138 \pm 16$ & $136 \pm 34$ \\
\hline $\mathrm{V}(\mathrm{ae}) / \mathrm{BW}(\mu \mathrm{L} / \mathrm{g})$ & $7.65 \pm 0.75$ & $7.83 \pm 0.93$ & $7.97 \pm 1.64$ & $8.15 \pm 1.10$ & $8.04 \pm 1.86$ \\
\hline $\mathrm{MCL}(\mu \mathrm{m})$ & $18.82 \pm 2.07$ & $29.35 \pm 4.07^{* * * *}$ & $28.56 \pm 4.58^{* * * *}$ & $28.52 \pm 2.31^{* * * *}$ & $27.81 \pm 5.93 * * * *$ \\
\hline MSWT $(\mu \mathrm{m})$ & $6.71 \pm 0.49$ & $6.48 \pm 0.70$ & $6.53 \pm 0.41$ & $6.45 \pm 0.65$ & $6.67 \pm 0.57$ \\
\hline
\end{tabular}

Values represent means \pm SD. Experimental animals were treated with $0.1 \times 10^{6}$ (MSC low), $0.5 \times 10^{6}$ (MSC medium), or $1 \times 10^{6}$ (MSC high) MSCs via the i.n. route.

${ }^{*} P<0.05,{ }^{* *} P<0.01,{ }^{* * *} P<0.001$, and ${ }^{* * * *} P<0.0001$ versus PBS i.n. normoxia.

$\mathrm{A}_{\mathrm{A}}(\mathrm{ae} / \mathrm{lu})$, areal density of air-exchanging parenchyma; $\mathrm{BW}$, body weight; MCL, mean cord length; MSWT, mean septal wall thickness; $\mathrm{V}(\mathrm{ae})$, volume of air-exchanging parenchyma; $V(l u)$, inflated lung volume.

animals revealed expanded, simplified airspaces, contrasting with the complex alveolar network of smaller, polygonal airspaces seen in normoxic controls (Figure 1, A and B).

Stereologic volumetry demonstrated a significant reduction in $\mathrm{A}_{\mathrm{A}}(\mathrm{ae} / \mathrm{lu})$ and $\mathrm{V}(\mathrm{ae})$ in hyperoxic versus normoxic control animals, whereas the ratio of $\mathrm{V}(\mathrm{ae})$ to body weight remained equivalent between both groups (Figure $1 \mathrm{E}$ and Tables 1 and 2). In agreement with their emphysema-like lung morphology, the mean cord length of hyperoxic controls was significantly $(56 \%)$ larger than that of normoxic controls, reflective of diminished alveolar septation (alveolar simplification) (Figure $1 F$ ). The mean septal wall thickness of hyperoxic controls was slightly smaller than that of normoxic controls (difference not statistically significant) (Figure $1 \mathrm{G}$ and Tables 1 and 2).
After establishment of baseline values in normoxic and hyperoxic PBS-treated control animals, we determined the effects of i.p. or i.n. administration of MSCs (low dose, $0.1 \times 10^{6}$; medium dose, $0.5 \times 10^{6}$; and high dose, $1 \times 10^{6}$ ) on somatic and lung growth 8 weeks after transplantation. The i.n. administration of MSCs had no significant effects on body weight or lung growth (Table 1). Similarly, i.n. MSCs had no effect on alveolar remodeling, as assessed by light microscopy (Figure $1 \mathrm{C}), \mathrm{A}_{\mathrm{A}}(\mathrm{ae} / \mathrm{lu})$, mean cord length, and mean septal wall thickness (Figure 1, E-G).

The i.p. MSC administration tended to be associated with a further reduction in body weight in hyperoxic animals (means \pm SD body weight: $15.80 \pm 2.78 \mathrm{~g}$ in the high-dose MSC group versus $18.08 \pm 2.21 \mathrm{~g}$ in hyperoxic controls; difference not statistically significant) (Table 2). The

Table 2 Biometry and Lung Morphometry ( $90 \% \mathrm{O}_{2}$ Experiment) for I.P. Administration of MSCs

\begin{tabular}{|c|c|c|c|c|c|}
\hline Parameter & $\frac{\text { Normoxia }}{\text { PBS }(n=21)}$ & \multicolumn{4}{|l|}{ Hyperoxia } \\
\hline BW (g) & $21.04 \pm 3.19$ & $18.08 \pm 2.21$ & $16.21 \pm 2.14^{* *}$ & $16.41 \pm 3.20^{*}$ & $15.80 \pm 2.78^{* *}$ \\
\hline Heart weight (mg) & $161 \pm 29$ & $141 \pm 21$ & $128 \pm 23$ & $132 \pm 14$ & $127 \pm 28$ \\
\hline Heart weight/BW (\%) & $0.77 \pm 0.10$ & $0.78 \pm 0.09$ & $0.79 \pm 0.10$ & $0.81 \pm 0.09$ & $0.81 \pm 0.12$ \\
\hline $\mathrm{V}(\mathrm{lu})(\mu \mathrm{L})$ & $478 \pm 48$ & $471 \pm 50$ & $388 \pm 54$ & $426 \pm 82$ & $409 \pm 60$ \\
\hline$A_{A}(a e / l u)(\%)$ & $35.11 \pm 3.38$ & $29.98 \pm 2.46^{* *}$ & $32.27 \pm 3.98$ & $32.44 \pm 2.18$ & $32.25 \pm 3.10$ \\
\hline$V(a e)(\mu \mathrm{L})$ & $171 \pm 23$ & $141 \pm 16$ & $125 \pm 18^{* *}$ & $141 \pm 28$ & $133 \pm 33^{*}$ \\
\hline $\mathrm{V}(\mathrm{ae}) / \mathrm{BW}(\mu \mathrm{L} / \mathrm{g})$ & $8.00 \pm 1.24$ & $7.89 \pm 1.31$ & $7.99 \pm 0.80$ & $8.52 \pm 1.15$ & $8.47 \pm 0.88$ \\
\hline $\operatorname{MCL}(\mu \mathrm{m})$ & $18.92 \pm 1.92$ & $29.45 \pm 6.24^{* * * *}$ & $27.32 \pm 3.64^{* * *}$ & $27.94 \pm 5.11^{* * * *}$ & $27.18 \pm 3.40 * * *$ \\
\hline MSWT $(\mu \mathrm{m})$ & $6.70 \pm 0.46$ & $6.44 \pm 0.83$ & $6.56 \pm 0.71$ & $6.72 \pm 0.58$ & $7.48 \pm 0.71^{\dagger}$ \\
\hline
\end{tabular}

Values represent means \pm SD. Experimental animals were treated with $0.1 \times 10^{6}$ (MSC low), $0.5 \times 10^{6}$ (MSC medium), or $1 \times 10^{6}$ (MSC high) MSCs via the i.p. route.

${ }^{*} P<0.05,{ }^{* *} P<0.01,{ }^{* *} P<0.001$, and ${ }^{* * * *} P<0.0001$ versus PBS i.p. normoxia.

${ }^{\dagger} P<0.05$ versus PBS i.p. hyperoxia.

$\mathrm{A}_{\mathrm{A}}(\mathrm{ae} / \mathrm{lu})$, areal density of air-exchanging parenchyma; BW, body weight; MCL, mean cord length; MSWT, mean septal wall thickness; V(ae), volume of air-exchanging parenchyma; $\mathrm{V}(\mathrm{lu})$, inflated lung volume. 

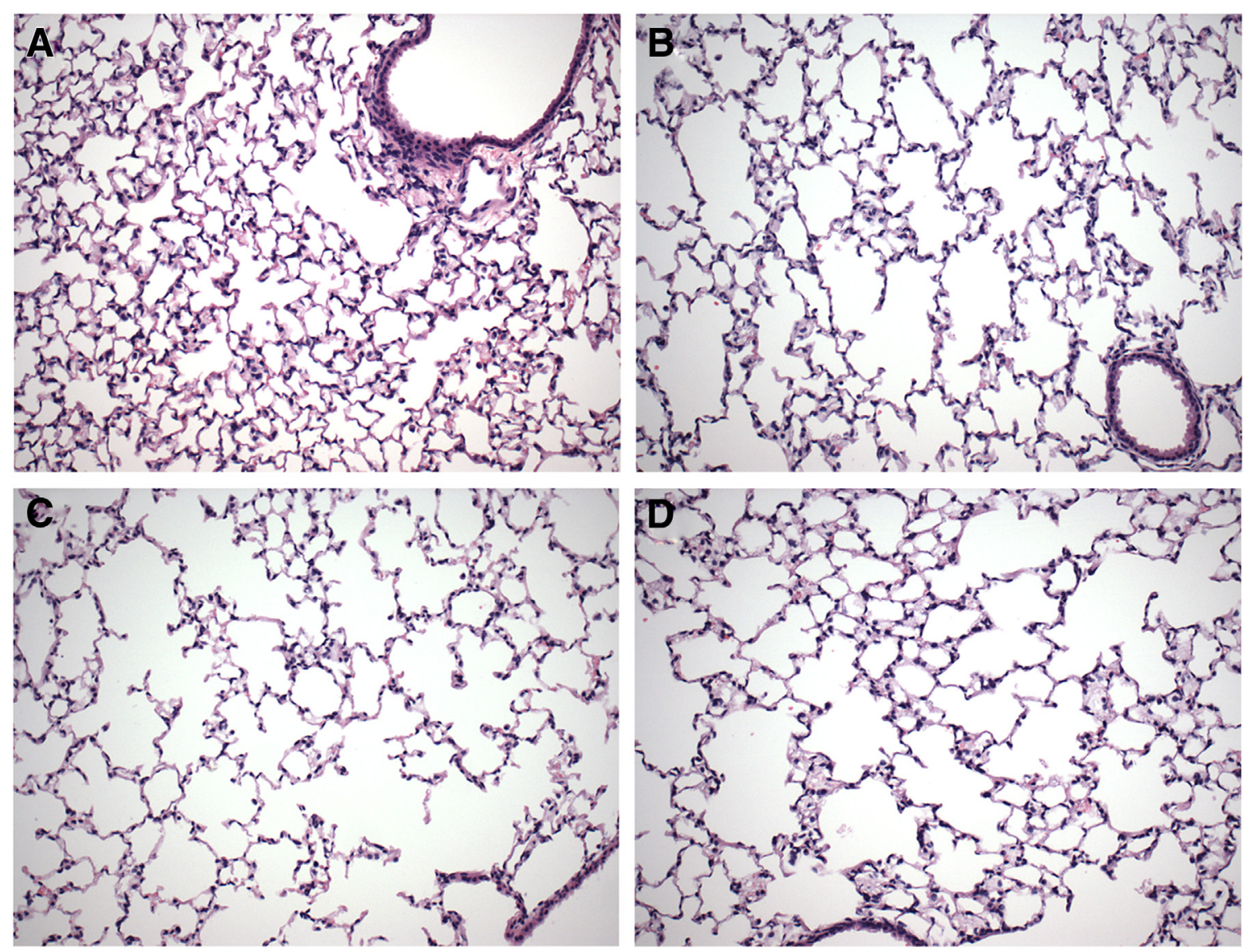

E
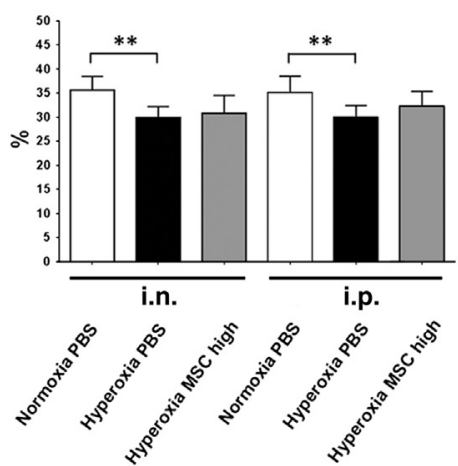

$\mathbf{F}$

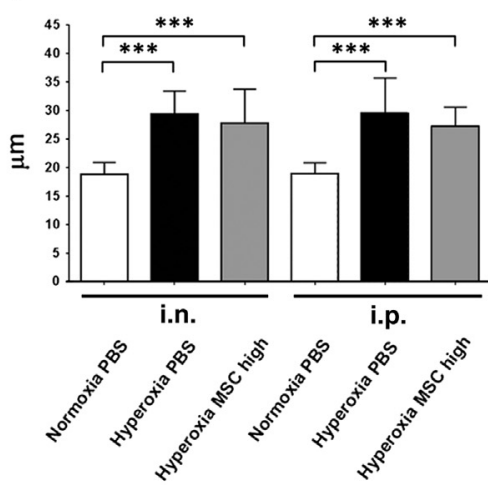

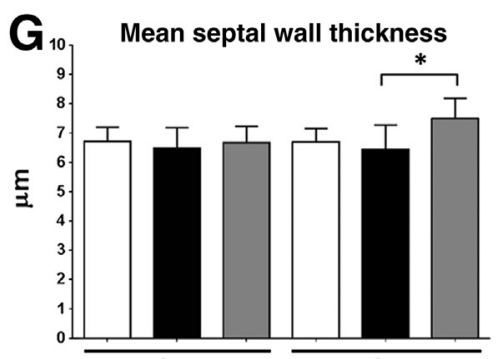

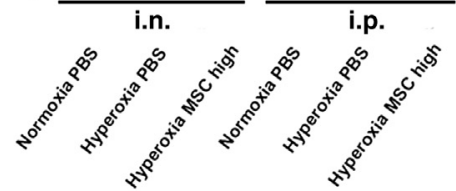

Figure 1 Analysis of alveolarization. A: Representative micrograph of a normoxia-exposed control animal at 9 weeks of age showing a complex alveolar network. B: Representative micrograph of a hyperoxia-exposed control animal exposed to $90 \% \mathrm{O}_{2}$ from birth until postnatal day 7 examined at 9 weeks of age. The airspaces are large and simplified, replicating the emphysema-like morphologic features of new BPD. C: Representative micrograph of a hyperoxia-exposed animal treated with $1 \times 10^{6} \mathrm{MSCs}$ via the i.n. route. D: Representative micrograph of a hyperoxia-exposed animal treated with $1 \times 10^{6} \mathrm{MSCs}$ via the i.p. route. E-G: Morphometric analysis of lungs 8 weeks after transplantation of $1 \times 10^{6}$ (high-dose) MSCs to hyperoxia-exposed newborn mice via intranasal (i.n.) or i.p. delivery. Controls were PBS-treated normoxic and hyperoxic animals. Hematoxylin and eosin staining was used (A-D). Values represent means \pm SD. $n \geq 6$ animals per group. ${ }^{*} P<0.05,{ }^{*} P<0.01$, and ${ }^{* * *} P<0.0001$. Original magnification: $\times 200$ (A-D).

morphologic features of i.p. MSC-treated lungs appeared similar to those of hyperoxia-exposed controls by light microscopic inspection (Figure 1D). The airspaces were enlarged, with obvious diminished alveolar septation compared with normoxic controls. Computer-assisted morphometric analysis revealed several tendencies in the i.p. MSC treatment group, specifically: a relative increase in means $\pm \mathrm{SD}$ of $\mathrm{A}_{\mathrm{A}}(\mathrm{ae} / \mathrm{lu})(32.25 \% \pm 3.10 \%$ in the highdose MSC group versus $29.98 \% \pm 2.46 \%$ in hyperoxic controls); a relative increase in the means $\pm \mathrm{SD}$ ratio of $\mathrm{V}(\mathrm{ae})$ to body weight $(8.47 \pm 0.88 \mu \mathrm{L} / \mathrm{g}$ in the high-dose MSC group versus $7.89 \pm 1.31 \mu \mathrm{L} / \mathrm{g}$ in hyperoxic controls); and a mild decrease in means \pm SD mean cord length $(27.18 \pm 3.40$ $\mu \mathrm{m}$ in the high-dose MSC group versus $29.45 \pm 6.24 \mu \mathrm{m}$ in 
Table 3 Mechanical Lung Function Parameters (90\% $0_{2}$ Experiment) for I.N. Administration of MSCs

\begin{tabular}{|c|c|c|c|c|c|}
\hline \multirow[b]{2}{*}{ Parameter } & \multirow{2}{*}{$\begin{array}{l}\text { Normoxia } \\
\text { PBS }(n=22)\end{array}$} & \multicolumn{4}{|l|}{ Hyperoxia } \\
\hline & & PBS $(n=10)$ & MSC low $(n=7)$ & MSC medium $(n=6)$ & MSC high $(n=7)$ \\
\hline Inspiratory capacity & $0.70(0.56-0.87)$ & $0.77(0.64-1.13)$ & $0.85^{*}(0.79-0.96)$ & $0.80(0.64-0.97)$ & $0.79(0.71-0.88)$ \\
\hline $\begin{array}{l}\text { Resistance of the } \\
\text { respiratory system }\end{array}$ & $0.57(0.4-0.69)$ & $0.59(0.49-0.86)$ & $0.53(0.50-0.79)$ & $0.55(0.49-0.69)$ & $0.56(0.51-0.69)$ \\
\hline $\begin{array}{l}\text { Compliance of the } \\
\text { respiratory system }\end{array}$ & $0.043(0.033-0.055)$ & $0.054^{* *}(0.046-0.072)$ & $0.055^{*}(0.051-0.063)$ & $0.054(0.041-0.064)$ & $0.053^{*}(0.044-0.065)$ \\
\hline $\begin{array}{l}\text { Elastance of the respiratory } \\
\text { system }\end{array}$ & $23.40(18.29-29.98)$ & $18.54^{* *}(14.04-21.80)$ & $18.24^{* *}(15.85-19.61)$ & $18.63^{*}(15.55-24.38)$ & $18.96^{*}(15.31-22.66)$ \\
\hline Tissue damping & $3.97(3.38-4.98)$ & $3.87(3.13-4.51)$ & $3.67(3.23-4.45)$ & $3.55(3.30-4.22)$ & $3.47(3.28-5.01)$ \\
\hline Tissue elastance & $22.26(19.46-27.40)$ & $15.15^{* * * *}(10.56-18.29)$ & $15.63^{* * * *}(13.01-17.56)$ & $17.05^{* * *}(14.22-21.35)$ & $16.23^{* * *}(12.23-18.91)$ \\
\hline Tissue hysteresivity & $0.17(0.15-0.22)$ & $0.24^{\star * * *}(0.21-0.30)$ & $0.23^{* \star * *}(0.20-0.34)$ & $0.22 *(0.19-0.24)$ & $0.24^{* * *}(0.19-0.27)$ \\
\hline Quasi-static compliance & $0.070(0.055-0.094)$ & $0.079(0.064-0.116)$ & $0.090 * *(0.083-0.104)$ & $0.088(0.069-0.103)$ & $0.084(0.076-0.102)$ \\
\hline Total lung capacity & $0.707(0.559-0.855)$ & $0.755(0.626-1.092)$ & $0.845^{*}(0.776-0.936)$ & $0.785(0.635-0.945)$ & $0.774(0.700-0.941)$ \\
\hline K & $0.167(0.151-0.186)$ & $0.187^{* * * *}(0.176-0.199)$ & $0.1885^{\star * * *}(0.177-0.198)$ & $0.190^{* * * *}(0.179-0.207)$ & $0.190 * * * *(0.185-0.196)$ \\
\hline
\end{tabular}

Values represent medians (minimums-maximums). Experimental animals were treated with $0.1 \times 10^{6}$ (MSC low), $0.5 \times 10^{6}$ (MSC medium), or $1 \times 10^{6}$ (MSC high) MSCs via the i.n. route.

${ }^{*} P<0.05,{ }^{* *} P<0.01,{ }^{* *} P<0.001$, and ${ }^{* * * * P}<0.0001$ versus PBS i.n. normoxia.

$K$, curvature of the upper portion of the deflation PV curve.

hyperoxic controls) (Table 2 and Figure 1, E and F). The means \pm SD septal wall thickness of MSC-treated hyperoxic animals (high dose) was significantly larger than that of hyperoxic control animals $(7.48 \pm 0.71 \mu \mathrm{m}$ versus $6.44 \pm 0.83 ; P<0.05$ ) (Figure $1 \mathrm{G}$ ), consistent with MSCrelated modification of the pulmonary interstitium.

\section{Functional Effects of MSC Administration to Hyperoxic Newborn Mice}

We observed that i.p. MSC administration to hyperoxic newborn pups was associated with significant alveolar septal widening and modest alteration of other morphometric outcome parameters of alveolarization, such as mean cord length and $\mathrm{A}_{\mathrm{A}}(\mathrm{ae} / \mathrm{lu})$. The i.n. administration of MSCs had no morphologic or morphometric effects. To determine whether MSC administration had any lasting functional effects, lung mechanics were studied by forced oscillation technique (flexiVent ventilator) 8 weeks after i.p. or i.n. administration of MSCs (low, medium, or high dose) or PBS. We first compared the lung mechanics of PBS-treated normoxic controls with those of hyperoxia-exposed controls to determine whether neonatal exposure to $90 \% \mathrm{O}_{2}$ has any long-term functional effects. As shown in Tables 3 and 4, this severe neonatal hyperoxia regimen resulted in significantly increased pulmonary compliance (compliance of the respiratory system and

Table 4 Mechanical Lung Function Parameters ( $90 \% 0_{2}$ Experiment) for I.P. Administration of MSCs

\begin{tabular}{|c|c|c|c|c|c|}
\hline \multirow[b]{2}{*}{ Parameter } & \multirow{2}{*}{$\begin{array}{l}\text { Normoxia } \\
\text { PBS }(n=21)\end{array}$} & \multicolumn{4}{|l|}{ Hyperoxia } \\
\hline & & $\mathrm{PBS}(n=11)$ & MSC low $(n=7)$ & MSC medium $(n=7)$ & MSC high $(n=7)$ \\
\hline Inspiratory capacity & $0.71(0.55-0.82)$ & $0.87^{* *}(0.70-0.98)$ & $0.73(0.66-1.03)$ & $0.81(0.67-1.05)$ & $0.62^{\dagger}(0.56-0.96)$ \\
\hline $\begin{array}{l}\text { Resistance of the } \\
\text { respiratory system }\end{array}$ & $0.57(0.51-0.80)$ & $0.57(0.49-0.71)$ & $0.57(0.48-0.66)$ & $0.54(0.49-0.72)$ & $0.62(0.49-1.02)$ \\
\hline $\begin{array}{l}\text { Compliance of the } \\
\text { respiratory system }\end{array}$ & $0.044(0.034-0.051)$ & $0.059^{* * * *}(0.045-0.072)$ & $0.048(0.042-0.068)$ & $0.050(0.043-0.072)$ & $0.044^{\ddagger}(0.033-0.064)$ \\
\hline $\begin{array}{l}\text { Elastance of the respiratory } \\
\text { system }\end{array}$ & $22.97(19.72-29.85)$ & $17.05^{\star * * *}(13.87-22.18)$ & $20.91(14.68-23.62)$ & $20.05(13.94-23.44)$ & $23.18^{\ddagger}(15.56-30.23)$ \\
\hline Tissue damping & $3.84(3.20-4.98)$ & $3.54(2.69-4.23)$ & $3.99(2.85-5.03)$ & $3.58(2.77-5.11)$ & $4.29^{* \pm}(3.26-6.77)$ \\
\hline Tissue elastance & $22.36(19.33-28.13)$ & $13.97^{* * * *}(12.15-19.40)$ & $18.27^{* *}(13.44-20.69)$ & $18.09^{* * *}(13.25-20.04)$ & $20.37^{\ddagger}(13.49-24.74)$ \\
\hline Tissue hysteresivity & $0.175(0.14-0.19)$ & $0.23^{* * * *}(0.22-0.30)$ & $0.22^{* *}(0.19-0.26)$ & $0.215^{*}(0.17-0.27)$ & $0.23^{* * * *}(0.20-0.32)$ \\
\hline Quasi-static compliance & $0.071(0.056-0.081)$ & $0.088^{\star *}(0.073-0.104)$ & $0.078(0.070-0.110)$ & $0.087^{*}(0.073-0.116)$ & $0.067(0.053-0.102)$ \\
\hline Total lung capacity & $0.711(0.558-0.812)$ & $0.844^{*}(0.688-0.963)$ & $0.721(0.655-0.997)$ & $0.794(0.660-1.026)$ & $0.612^{\dagger}(0.543-0.937)$ \\
\hline $\mathrm{K}$ & $0.1645(0.150-0.179)$ & $0.184^{\star * * *}(0.176-0.198)$ & $0.191^{* * * *}(0.180-0.198)$ & $0.1875^{* * * *}(0.178-0.205)$ & $0.1815^{*}(0.148-0.197)$ \\
\hline
\end{tabular}

Values represent medians (minimum-maximum). Experimental animals were treated with $0.1 \times 10^{6}$ (MSC low), $0.5 \times 10^{6}$ (MSC medium), or $1 \times 10^{6}$ (MSC high) MSCs via the i.p. route.

${ }^{*} P<0.05,{ }^{* *} P<0.01,{ }^{* *} P<0.001$, and ${ }^{* * * *} P<0.0001$ versus PBS i.p. normoxia.

${ }^{\dagger} P<0.05$

${ }^{\ddagger} P<0.01$ versus PBS i.p. hyperoxia.

$K$, curvature of the upper portion of the deflation PV curve. 

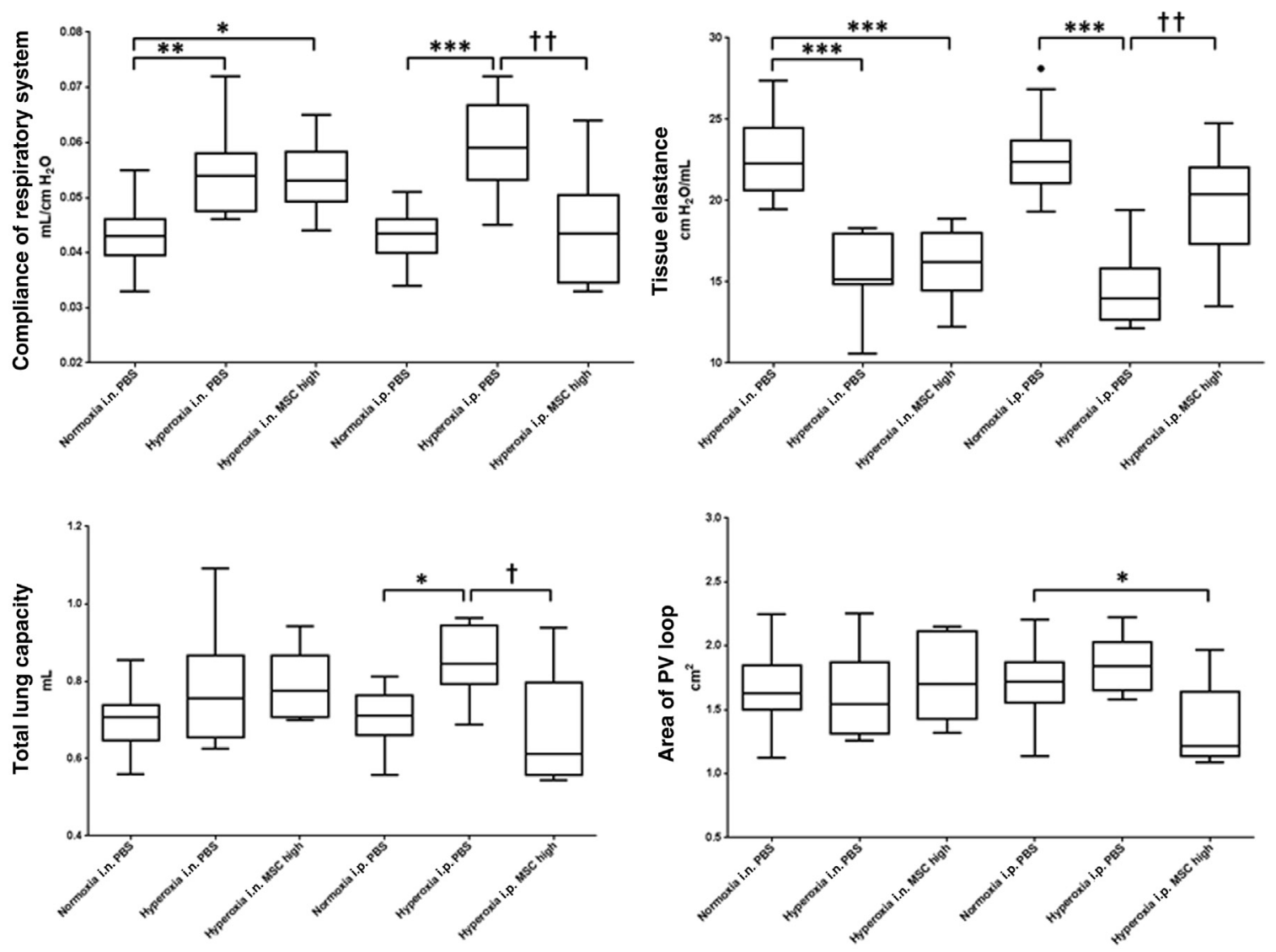

Figure 2 Analysis of lung mechanics. Pulmonary function tests 8 weeks after transplantation of $1 \times 10^{6}$ (high-dose) MSCs to hyperoxia-exposed newborn mice via i.n. or i.p. delivery. Controls were PBS-treated normoxic and hyperoxic animals. Presented are selected data obtained by snapshot (compliance of the respiratory system) and Quickprime-3 (tissue elastance) perturbations and maximal PV loops [total lung capacity and hysteresis (area between inflating and deflating part of the loop)] by flexiVent ventilator technique in tracheotomized mice. Boxplot analyses represent group median, upper and lower quartiles (box), maximum and minimum values excluding outliers (whiskers), and outliers (more than $3 / 2$ times the upper quartile) (bullets). Not all the parameters are provided in this figure (see Tables 3 and 4 for complete data). ${ }^{*} P<0.05,{ }^{*} P<0.01$, and ${ }^{* * *} P<0.0001$ versus normoxic controls; ${ }^{\dagger} P<0.05,{ }^{\dagger \dagger} P<0.01$ versus hyperoxic controls. $n \geq 6$ animals per group.

quasi-static compliance), reduced elastance (elastance of the respiratory system and tissue elastance), increased inspiratory capacity, increased hysteresivity, increased total lung capacity (Salazar-Knowles parameter A), and increased curvature of the upper portion of the deflation PV curve (Salazar-Knowles parameter K) in adulthood. In contrast, neonatal hyperoxia exposure had no lasting effects on central airway resistance (Newtonian resistance), resistance of the respiratory system, or area of the PV loop (Tables 3 and 4).

After determination of the baseline lung mechanics of hyperoxia-exposed control animals, we studied the long-term functional effects of neonatal MSC administration. The i.n. MSC administration had no obvious effects on any of the lung function parameters studied, specifically: the pulmonary compliance, elastance, hysteresivity, and inspiratory capacity of animals treated with i.n. MSCs were similar to those of hyperoxic PBS-treated controls, regardless of the MSC dose used (Table 3). In contrast, i.p. MSC administration had a significant and seemingly dose-dependent effect on several lung function parameters. At the highest dose studied $\left(1 \times 10^{6}\right.$ cells $)$, i.p. MSCs effectively restored inspiratory capacity, compliance of the respiratory system, quasi-static compliance, elastance of the respiratory system, and tissue elastance to normoxic levels (Table 4). The i.p. MSCs further significantly reduced the total lung capacity and area of the PV loop of hyperoxic animals, reaching levels below those seen in normoxic animals. Even at the highest dose, i.p. MSCs had no obvious effects on airway resistance (Newtonian resistance), resistance of the respiratory system, or tissue hysteresivity (Tables 3 and 4 ). Selected functional parameters are shown in Figure 2.

$\mathrm{PV}$ loops were generated using the data provided by the stepwise PVr-P maneuver. For the sake of clarity, only data for PBS-treated normoxic and hyperoxic controls and for hyperoxic animals treated with high-dose MSCs are shown in Figure 3. In PBS-treated control animals, neonatal hyperoxia exposure was associated with an upward shift of the PV curve in adulthood, consistent with an emphysematous pulmonary phenotype (Figure 3). The i.n. MSC administration had no obvious effects on the position or shape of the PV loop at any dose; in fact, the PV loop of hyperoxia-exposed, i.n. MSC-treated animals at low, medium, or high doses showed almost perfect alignment with that of hyperoxic controls 

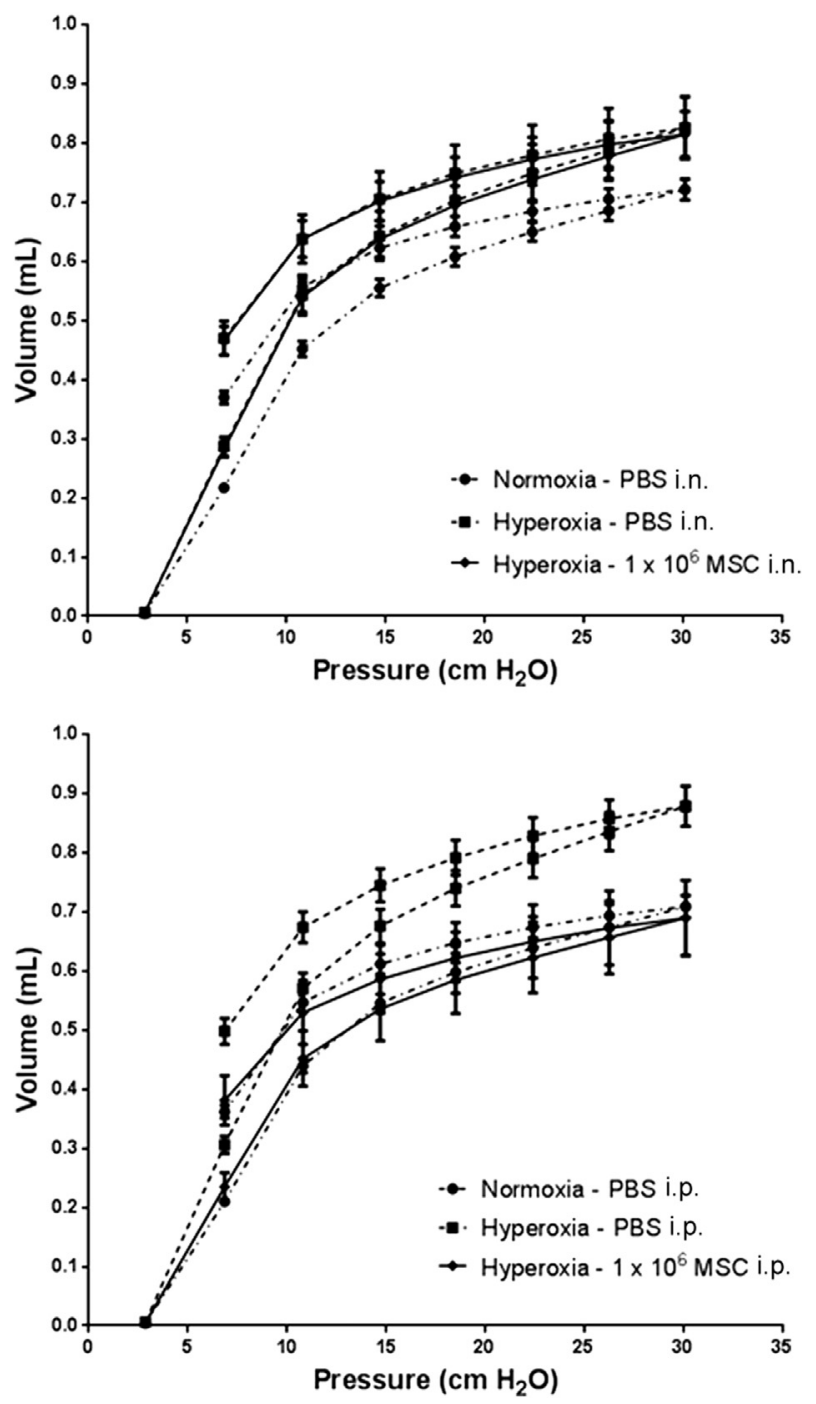

Figure 3 Analysis of lung mechanics: PV loops - ramp pressure regulated (PVr-P). PV loops were generated using the PVr-P perturbation from the flexiVent ventilator. Graphs represent means \pm SD. $n \geq 6$ animals per pressure point per group.

(Figure 3). In contrast to the lack of effects seen after i.n. MSC administration, i.p. high-dose MSC administration was associated with a dramatic downward shift of the hyperoxic PV loops to reach normoxic levels (Figure 3). This downward shift was associated with closer approximation of inspiration and expiration curves, consistent with the reduction in area of the PV loop described in the previous paragraph and in Figure 2. The PV loops of animals treated with low- or medium-dose i.p. MSCs were positioned intermediate between those of PBS-treated hyperoxic controls and those of animals treated with high-dose i.p. MSCs (not shown).

Taken together, these lung mechanics studies suggest that neonatal hyperoxia exposure leads to an emphysema-like functional phenotype in adulthood characterized by increased compliance and decreased elasticity (diminished tissue recoil). The i.p. administration of high-dose $\left(1 \times 10^{6}\right.$ per pup) MSCs during the neonatal period resulted in restoration or preservation of normal lung compliance and elasticity 8 weeks after transplantation, suggestive of normalization of tissue recoil. Irrespective of dose, i.n. MSCs had no obvious effects on lung function.

Analysis of Early Pulmonary and Systemic Distribution of MSCs in Newborn Mice after i.n. or i.p.

\section{Administration}

We studied cell fate and distribution within 48 hours of i.n. and i.p. administration in a small number of animals $(n=4$ per delivery route). We sought to understand the mechanisms underlying the observed functional effects of MSCs after i.p. delivery and the lack of effect after i.n. delivery. The dispersion of i.n. or i.p. administered MSCs $\left(1 \times 10^{6}\right)$ to lungs and selected organs was monitored by anti-human vimentin immunohistochemical analysis. The i.n. administration of MSCs in newborn mice resulted in even and effective cellular distribution in both lungs (Figure 4A), confirming previous results with murine whole bone marrow or human $\mathrm{CD} 34^{+}$ hematopoietic progenitor cells. ${ }^{17,40}$ There was no obvious histopathologic evidence of an associated inflammatory response. No human vimentin-positive cells were detected in the liver, spleen, bone marrow, or kidneys (not shown). As expected after i.n. inoculation, very rare human vimentinpositive cells were detected in the lumen of the gastrointestinal tract, reflective of occasional spillage of cells from the upper respiratory tract (Figure 4B).

We studied the short-term pulmonary and systemic distribution of MSCs 48 hours after i.p. administration. No vimentin-immunoreactive MSCs were detected in the lung parenchyma of any of four animals examined. Similarly, no human vimentin-immunoreactive cells were seen in the spleen, liver, kidneys, or bone marrow (not shown). However, examination of the remaining abdominal contents, subjected to histologic analysis in toto, revealed the presence of MSCs in all the animals, stably embedded in peritoneal or retroperitoneal organs and soft tissues. These human vimentin-positive cells were detected as single cells, small clusters, or even distinct, highly cellular nodular aggregates displaying brisk proliferative activity (Figure 4, $\mathrm{C}-\mathrm{F}$ ). Omission of primary anti-vimentin antibody abolished all immunoreactivity. Anti-human vimentin staining of tissues of control newborn mice that did not receive MSCs was uniformly negative (not shown).

\section{Analysis of Long-Term Engraftment of MSCs or Their Progeny in Lungs and Other Organs of Newborn Mice}

The pulmonary and systemic presence of MSCs or MSCderived cells 8 weeks after transplantation was studied by human-specific alu-FISH analysis. These studies were limited to animals treated with the high-dose $\left(1 \times 10^{6}\right.$ cells per pup $)$ regimen. Rare alu-FISH-positive nuclei were identified in the lungs of all MSC recipient animals, regardless of delivery 


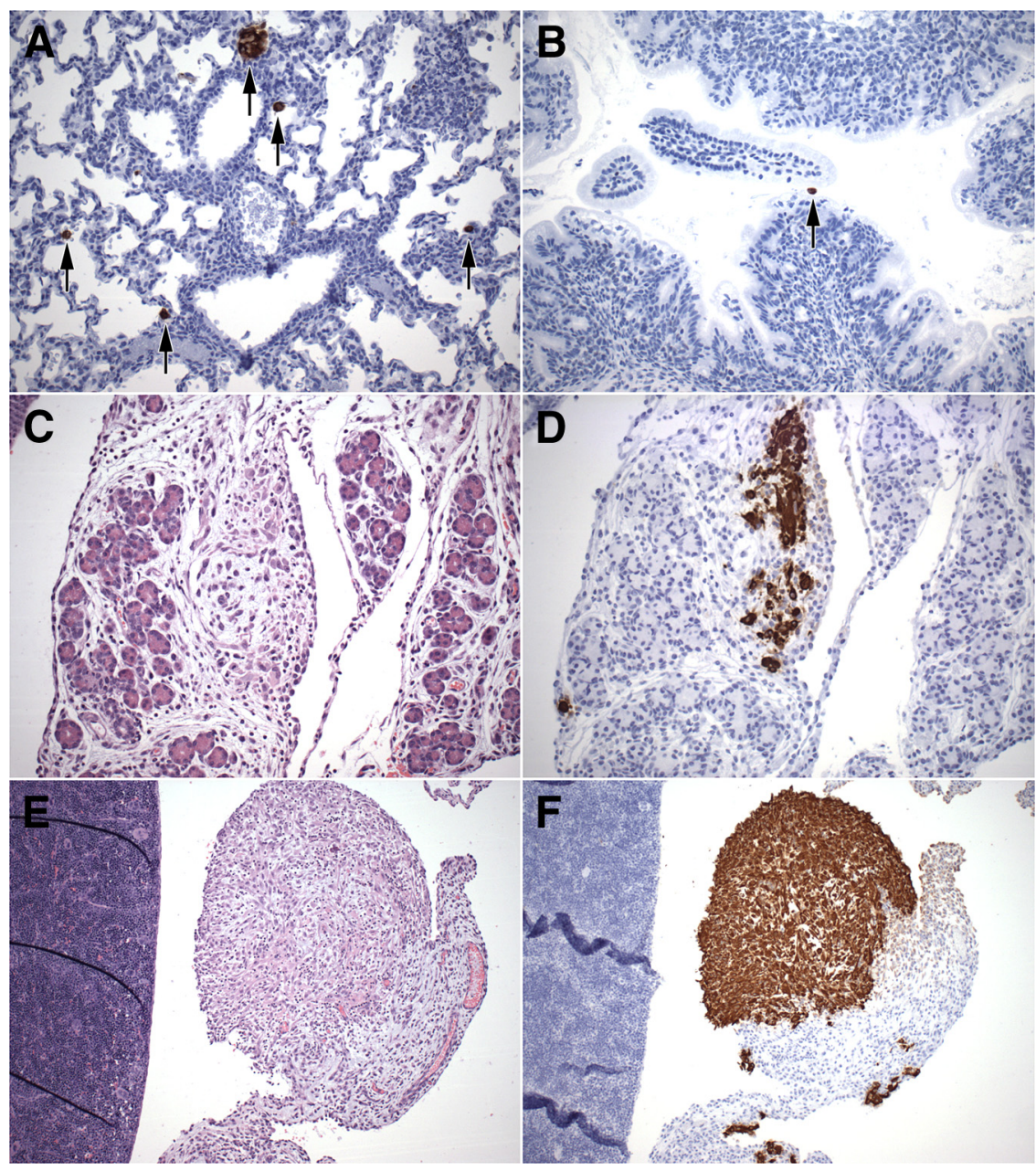

Figure 4 Analysis of MSC distribution 48 hours after i.n. or i.p. administration. A: Representative anti-human vimentin staining of the lungs of an animal treated with $1 \times 10^{6} \mathrm{MSC}$ i.n. Numerous human vimentin-positive single or aggregated MSCs are seen distributed in peribronchial and more distal lung parenchyma (arrows). Murine mesenchymal cells, such as fibroblasts, endothelial cells, and peribronchial/perivascular smooth muscle cells, show no cross-reactivity with the anti-human vimentin antibody, supporting its specificity for human cells. B: Anti-human vimentin staining of the intestinal tract of an animal treated with $1 \times 10^{6} \mathrm{MSC}$ i.n. A single MSC is seen in the lumen (arrow), consistent with occasional spillage of very small numbers of i.n.-delivered cells into the gastrointestinal tract. C-D: Micrograph and anti-human vimentin staining of the pancreas and peripancreatic soft tissue of an animal treated with $1 \times 10^{6} \mathrm{MSC}$ i.p. Isolated and clustered MSCs are embedded in the peripancreatic soft tissue, associated with mild mesothelial and stromal reactive changes. $\mathbf{E}$ and $\mathbf{F}$ : Micrograph and anti-human vimentin staining of perisplenic soft tissue, possibly omentum, of an animal treated with $1 \times 10^{6}$ MSCs i.p. A large-sized nodular aggregate of MSCs is seen protruding from the soft tissue. Several scattered smaller MSC aggregates are noted. Avidin-biotin peroxidase staining, hematoxylin counterstain (A, B, D, and F); hematoxylin and eosin staining ( $\mathbf{C}$ and $\mathbf{E})$. Original magnification: $\times 200(\mathbf{A}-\mathbf{D}) ; \times 100(\mathbf{E}$ and $\mathbf{F})$.

route (Figure 5). The engrafted cells seemed to be randomly distributed in central and peripheral lung parenchyma, without obvious topographic predilection. Most MSC-derived cells were single, although occasionally alu-FISH-positive cells were seen as doublets or triplets, suggestive of recent clonogenic expansion (Figure 5, A and C). In support of this interpretation, occasional proliferative activity was detected in engrafted MSC-derived cells by combined alu-FISH analysis and Ki-67 immunostaining in the i.n. and i.p. treatment groups (Figure 5B). In view of the low numerical density of MSCderived cells in either delivery group, no formal quantitation was performed. The systemic presence of MSC-derived cells was studied by vimentin staining and alu-FISH analysis of selected organs. No human-derived cells were detected in random sections of liver, spleen, heart, or kidneys (not shown).

Taken together, the short- and long-term cellular distribution studies indicate that i.n. administration results in homogenous distribution solely in the lung parenchyma. After i.p. administration, cells tended to remain in the peritoneum or retroperitoneum, although eventually some disseminated to and were retained in the lungs. The viability of cells in the peritoneal cavity and their virtual absence in lungs immediately after transplantation suggest that any pulmonary effects from i.p. MSC administration are likely attributable to systemic paracrine effects rather than to direct structural integration. Unfortunately, no detailed examination of abdominal organs and/or peritoneal or retroperitoneal soft tissues 8 weeks after transplantation to assess long-term persistence of MSCs in these locations was performed.

\section{Analysis of Cellular Composition of Bronchoalveolar Lavage Fluid 8 Weeks after Transplantation}

The paucity of intrapulmonary human-derived cells detected 8 weeks after transplantation in this study supports the growing notion that the pulmonary effects of stem cells, regardless of cell type, are based on paracrine, antiinflammatory and/or immunomodulatory, activities of the cells. To begin to explore this potential role in the transplant model, we examined the morphologic features of cells in the bronchoalveolar lavage fluid 8 weeks after transplantation.

The cellular composition of the lavage fluid was equivalent among the various treatment groups: in all groups, alveolar macrophages accounted for $>95 \%$ of cells. Variable numbers of scattered lymphocytes and rare eosinophils composed the remaining 5\%. Although the cellular composition was similar, the appearance of alveolar macrophages varied among the various treatment groups. Compared with normoxic controls, 


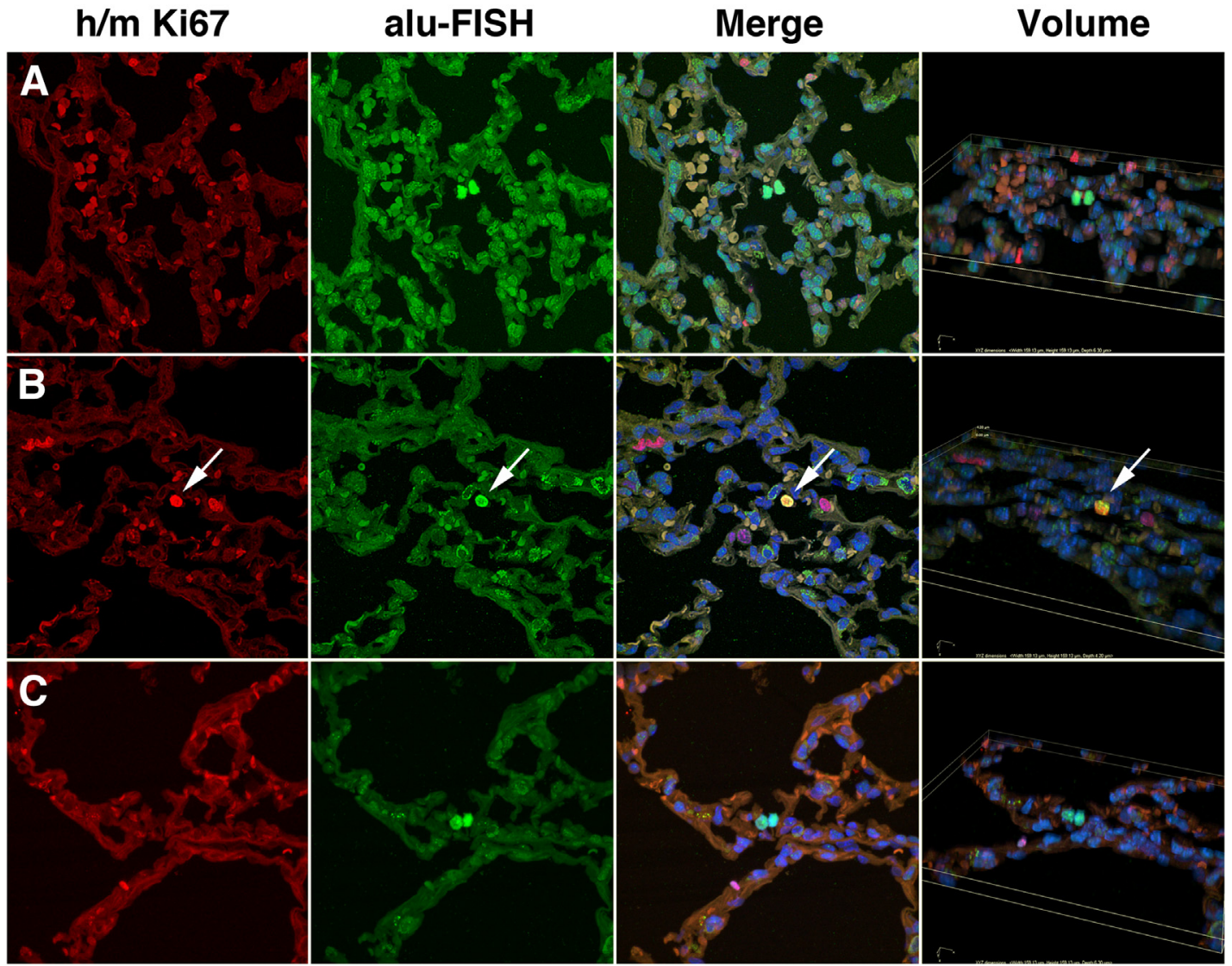

Figure 5 Analysis of engraftment and proliferation of human MSC-derived cells. Confocal fluorescence microscopy of lungs subjected to combined anti-Ki-67 immunofluorescence (red) and alu-FISH analysis (green), and DAPI counterstain (blue). A: Representative micrograph of the lungs of an animal treated with $1 \times 10^{6}$ MSCs i.n. shows a doublet of alu-FISH-positive cells (green) along the alveolar wall. Several proliferating FISH-negative murine cells are noted (red). B: Representative micrograph of the lungs of an animal treated with $1 \times 10^{6} \mathrm{MSC}$ i.n. shows a proliferating alu-FISH-positive cell (yelloworange; arrows) along the alveolar wall. Cytoplasmic granular green autofluorescence noted in several large-sized cells is consistent with the presence of hemosiderin pigment in murine alveolar macrophages. C: Representative micrograph of the lungs of an animal treated with $1 \times 10^{6}$ MSCs i.p. shows a doublet of alu-FISH-positive cells (green) along the alveolar wall.

the lavage fluid of hyperoxia-exposed control animals contained a relatively high proportion of macrophages containing cytoplasmic granules of heterogeneous size and shape (Figure 6, A and B). These cytoplasmic granules were morphologically consistent with hemosiderin; positive Perls staining confirmed the iron content of the cytoplasmic granules (Figure 6E). We compared the presence of hemosiderin-laden macrophages in MSC-treated animals (high dose) (Figure 6, C and D) and observed that the fraction of hemosiderin-laden macrophages was significantly lower in animals treated with i.p. MSCs than in hyperoxic controls (Figure 6F). The lower fraction of hemosiderin-laden macrophages 8 weeks after transplantation suggests that acute, hemorrhagic lung injury induced by hyperoxia exposure may have been shortened or attenuated by high-dose i.p. MSC treatment.

\section{Discussion}

Clinical trials investigating the efficacy and short-term safety of MSC therapy in newborns with BPD are currently in progress. ${ }^{38}$ The initial published results of the first completed small-scale clinical trial seem to demonstrate that MSC cell therapy may be safe and have modest, short-term beneficial effects. ${ }^{38} \mathrm{~A}$ better understanding of the role of the many variables involved in successful MSC therapy, including route of administration and dose response, may contribute to the optimization of future clinical trials. Herein, we performed a systematic comparative analysis of the functional and morphologic effects of cultured human cord tissue MSCs administered via either the systemic (i.p.) or intrapulmonary (i.n.) route. Cells $\left(0.1,0.5\right.$, or $1 \times 10^{6}$ cells per pup) were administered during the newborn period (postnatal day 5) to immunosuppressed severe combined immunodeficiency-beige mice with hyperoxia-induced neonatal lung injury; the functional and morphologic/morphometric outcomes were assessed 8 weeks after transplantation.

Lung mechanics were assessed by the invasive forced oscillation technique (flexiVent ventilator), which provides accurate and reproducible estimation of critical parameters, such as compliance, elastance, and resistance of the rodent respiratory system. ${ }^{43}$ In agreement with similar studies by 


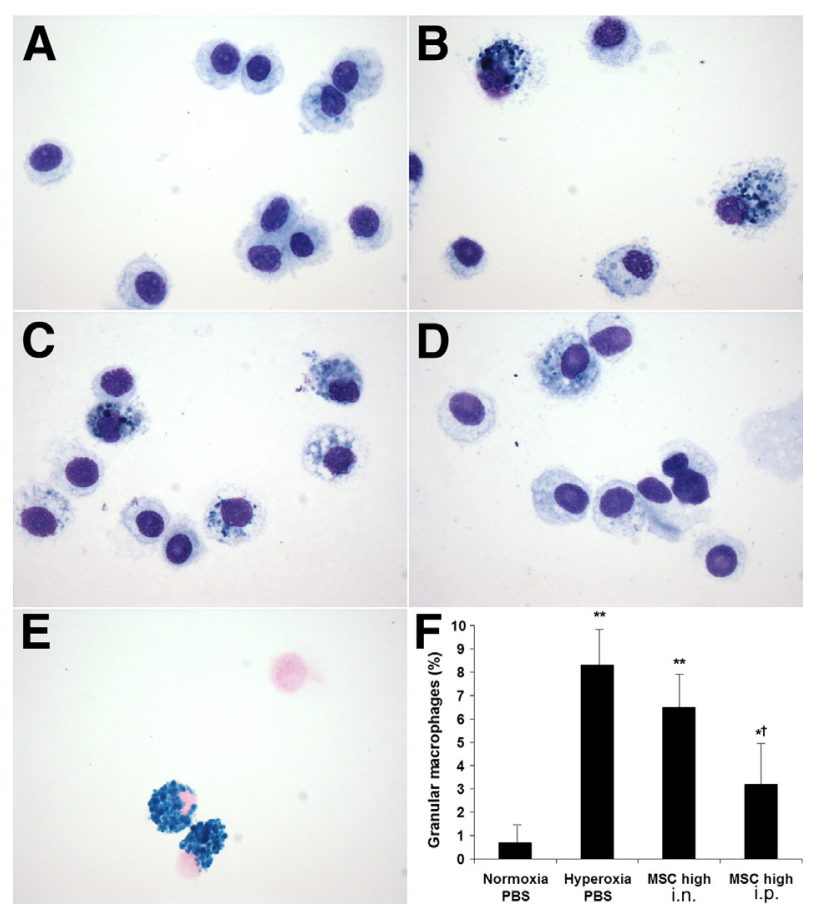

Figure 6 Analysis of bronchoalveolar lavage fluid. A-D: Representative morphology of alveolar macrophages. A: Normoxia, PBS control. B: Hyperoxia, PBS control. C: Hyperoxia, MSC high i.n. D: Hyperoxia, MSC high, i.p. Cytoplasmic granules are more frequent and conspicuous in alveolar macrophages of hyperoxia-exposed animals than in normoxic controls. E: Perls iron staining of lavage fluid of a hyperoxia-exposed control animal showing two alveolar macrophages with abundant cytoplasmic hemosiderin granules. F: Fraction of granule-containing alveolar macrophages, expressed as a percentage. Giemsa stain was used. Values represent means \pm SD. $n \geq 6$ animals per group. ${ }^{*} P<0.01,{ }^{* *} P<0.0001$ versus normoxic PBS-treated controls; ${ }^{\dagger} P<0.001$ versus hyperoxic PBStreated controls. Original magnification, $\times 1000$ (oil) (D).

Yee et $\mathrm{al}^{49}$ we first established that 1 week of hyperoxia exposure at $90 \% \mathrm{O}_{2}$ in the newborn period has long-lasting functional effects in adulthood characterized by significantly increased lung compliance and diminished elastance, associated with an upward shift of the PV loops. Increased lung compliance/reduced elastance is a functional hallmark of the loss of elastic recoil seen in pulmonary emphysema, ${ }^{43,50}$ and entirely consistent with the emphysema-like phenotype with simplified and enlarged airspaces typical of neonatal hyperoxia exposure in rodents ${ }^{39-41}$ and BPD in human preterm infants. $^{7-9}$

The i.p. administration of human cultured MSCs to hyperoxia-exposed newborn mice resulted in a dosedependent decrease in lung compliance (and a corresponding increase in elastance) by 8 weeks after transplantation. At the highest dose studied $\left(1 \times 10^{6}\right.$ MSCs per animal), i.p. MSC administration effectively restored/normalized lung compliance, elastance, and PV loops to normoxic control levels. The exact biochemical/structural correlates of the observed increased lung compliance/elastic recoil associated with i.p. MSC administration remain to be determined. Pulmonary elastic recoil is approximately equally determined by two main anatomical attributes of the lung parenchyma: the elastic properties of its interstitium and the unique structure and complexity of the liquid-filled alveolar network. ${ }^{51}$ As determined in this study, high-dose i.p. MSC delivery caused only a mild increase in alveolar septation (decrease in mean cord length). More strikingly, however, high-dose i.p. MSC delivery was associated with a significant increase in mean septal wall thickness, suggesting that the normalizing functional effects of IP MSCs were mediated, in large part, by modification of abundance and/or composition of the interstitial extracellular matrix, leading to improved pulmonary elastic recoil. Aslam et al ${ }^{14}$ recently reported similar beneficial, cytoprotective effects after systemic delivery of bone marrow-derived MSCs to hyperoxia-exposed newborn mice. In the study by Aslam et al, MSC administration resulted in a modest but significant increase in alveolar numbers and decreased, rather than increased, alveolar septal wall thickness in hyperoxia-exposed mice. Although the exact reason is unclear, it is likely that the different hyperoxia models ( $75 \%$ versus $90 \%$ ), mouse strains (FVB versus severe combined immunodeficiency-beige), MSC types (syngeneic mouse bone marrow derived versus xenogeneic human cord derived), study lengths (14 days versus 8 weeks), and delivery routes (i.v. versus i.p.) contributed to these divergent outcomes.

The apparent matrix-modulating effects of MSCs after i.p. administration are consistent with the functions of these mesenchymally active, potentially profibrotic cells. ${ }^{52}$ MSCs have been shown to stimulate lung fibroblast proliferation and matrix production, two characteristics of fibroproliferative lung disease. ${ }^{53}$ Although the relatively short-term (8-week) effects of i.p. MSCs in this study seemed to be beneficial and restored tissue recoil to baseline levels, the longer-term matrixmodulating effects of these mesenchymally active cells deserve close monitoring. Available preclinical data from various lines of investigation suggest that MSC administration may contribute to pulmonary fibrosis, at least in part, by differentiation into myofibroblasts. ${ }^{54-56}$

Whereas i.p. MSC delivery was found to have significant effects, i.n. delivery of MSCs from the same batch to the same host litter and at similar doses did not have any noticeable effects on lung mechanics. Specifically, i.n. inoculation of MSCs at doses ranging from 0.1 and $1 \times 10^{6}$ cells per pup did not affect lung compliance, elastance, PV loops, or resistance. Similarly, i.n. inoculation had no effects on alveolar remodeling or septal wall thickness. These results are in disagreement with other studies that reported beneficial effects of intratracheal MSCs on alveolar septation, lung vascular injury, and/or exercise intolerance in immunocompetent hyperoxia-exposed newborn rats. ${ }^{13,15,35}$ The reasons for these apparent discrepancies remain unclear. Differences in the timing of cell administration, model of neonatal lung injury, recipient strain, MSC cell processing, culturing, and donor effects may be implicated.

Evidence is continuously accumulating suggesting multiple immunomodulatory and anti-inflammatory paracrine 
effects of MSCs, either mediated directly by peptides/ growth factors or by transfer of exosomes, microvesicles, or organelles (reviewed by Weiss ${ }^{10,57}$ ). Detailed analysis of the biochemical and molecular underpinnings of the observed functional and morphologic effects of i.p. MSCs was beyond the scope of the present study. However, several of these findings support the notion that the observed effects of i.p. MSCs may be attributable to indirect, paracrine, antiinflammatory effects. In agreement with observations by others $^{58}$ (reviewed by Weiss ${ }^{10}$ ), structural integration of MSCs or their progeny into the lung parenchyma was only sporadic. Instead, the stable engraftment and brisk proliferative activity observed in peritoneal and retroperitoneal MSC implants studied immediately after transplantation suggests that these cells may have been capable of secretory activity for a prolonged period after administration.

Parenthetically, the cellular composition of the bronchoalveolar lavage fluid was equivalent between normoxic or hyperoxia-exposed controls and MSC-treated hyperoxiaexposed animals, consisting almost exclusively of alveolar macrophages in all groups. Closer examination revealed interesting differences between these groups with respect to the cellular features. Hemosiderin is a product of hemoglobin degradation, thus hemosiderin-laden alveolar macrophages are generally considered to be reflective of past intra-alveolar hemorrhage, such as may be seen in association with acute lung injury. As expected, the fraction of hemosiderincontaining macrophages was much higher in hyperoxiaexposed animals than in normoxic controls. The fraction of hemosiderin-laden macrophages was significantly lower in i.p. MSC-treated animals than in hyperoxic controls, suggesting that MSC administration in the newborn period may have attenuated or shortened the acute lung injury phase.

This study has some limitations. First, by design, the study focused on comparative analysis of effects of administration route and dose-dependent effects of a single, albeit randomly selected, MSC cell line. It is unclear how far the results obtained in this study can be extrapolated to other MSCs and their cell lines. Other researchers have described significant variability among MSCs from different tissue sources, different donors, and even within one cell line, from different passages (reviewed by Weiss $\left.{ }^{10}\right)$. Second, the exact anatomical and biochemical mechanisms underlying the observed improved tissue recoil after i.p. MSC administration, as well as their long-term consequences, remain to be resolved. Third, this study did not provide insight into the putative paracrine mechanisms underlying or contributing to the beneficial effects of i.p. MSCs.

In summary, these results suggest that i.p. (systemic) administration of cultured human MSCs at a high dose has the capacity to restore the lung mechanics (compliance, recoil) of hyperoxia-exposed newborn mice to normal levels, presumably by modification of the interstitial matrix. The brisk initial peritoneal engraftment of MSCs and low pulmonary engraftment levels suggest that these effects were mediated by paracrine factors rather than by direct structural regeneration of the injured lung parenchyma by
MSCs or their progeny. In contrast to the striking beneficial effects achieved by i.p. administration, i.n. inoculation of MSCs at the same dose had no effects on lung function or morphologic features. This study provides additional evidence of the beneficial therapeutic potential of MSCs in neonatal lung diseases and in adult lung diseases characterized by diminished tissue recoil, such as chronic obstructive lung disease/emphysema. Future studies will need to address the long-term safety of MSC therapy, especially when considered for use in newborns, as well as the importance of timing of MSC administration, donor and batch effects, and the molecular mechanisms underlying the observed functional effects of i.p.-delivered MSCs.

\section{Acknowledgments}

We thank Dr. Morey Kraus and Kate Falcon-Girard, RN, MSN, for advice and insight on experimental design and data analysis throughout these studies and Virginia Hovanesian for invaluable help with fluorescence and confocal microscopy.

\section{References}

1. Stoll BJ, Hansen NI, Bell EF, Shankaran S, Laptook AR, Walsh MC Hale EC, Newman NS, Schibler K, Carlo WA, Kennedy KA, Poindexter BB, Finer NN, Ehrenkranz RA, Duara S, Sanchez PJ, O'Shea TM, Goldberg RN, Van Meurs KP, Faix RG, Phelps DL, Frantz ID III, Watterberg KL, Saha S, Das A, Higgins RD: Neonatal outcomes of extremely preterm infants from the NICHD Neonatal Research Network. Pediatrics 2010, 126:443-456

2. Jobe AH: The new bronchopulmonary dysplasia. Curr Opin Pediatr 2011, 23:167-172

3. Bland RD: Neonatal chronic lung disease in the post-surfactant era. Biol Neonate 2005, 88:181-191

4. Costeloe KL, Hennessy EM, Haider S, Stacey F, Marlow N, Draper ES: Short term outcomes after extreme preterm birth in England: comparison of two birth cohorts in 1995 and 2006 (the EPICure studies). BMJ 2012, 345:e7976

5. Landry JS, Chan T, Lands L, Menzies D: Long-term impact of bronchopulmonary dysplasia on pulmonary function. Can Respir J 2011, 18:265-270

6. Vom Hove M, Prenzel F, Uhlig HH, Robel-Tillig E: Pulmonary outcome in former preterm, very low birth weight children with bronchopulmonary dysplasia: a case-control follow-up at school age. J Pediatr 2014, 164:40-45.e4

7. Husain AN, Siddiqui NH, Stocker JT: Pathology of arrested acinar development in postsurfactant bronchopulmonary dysplasia. Hum Pathol 1998, 29:710-717

8. Jobe AJ: The new BPD: an arrest of lung development. Pediatr Res 1999, 46:641-643

9. De Paepe ME, Mao Q, Powell J, Rubin SE, DeKoninck P, Appel N, Dixon M, Gundogan F: Growth of pulmonary microvasculature in ventilated preterm infants. Am J Respir Crit Care Med 2006, 173: 204-211

10. Weiss DJ: Stem cells, cell therapies, and bioengineering in lung biology and diseases. Comprehensive review of the recent literature 2010-2012. Ann Am Thor Soc 2013, 10:S45-S97

11. O'Reilly M, Thebaud B: Cell-based strategies to reconstitute lung function in infants with severe bronchopulmonary dysplasia. Clin Perinatol 2012, 39:703-725 
12. Alphonse RS, Rajabali S, Thebaud B: Lung injury in preterm neonates: the role and therapeutic potential of stem cells. Antioxid Redox Signal 2012, 17:1013-1040

13. van Haaften T, Byrne R, Bonnet S, Rochefort GY, Akabutu J, Bouchentouf M, Rey-Parra GJ, Galipeau J, Haromy A, Eaton F, Chen M, Hashimoto K, Abley D, Korbutt G, Archer SL, Thebaud B: Airway delivery of mesenchymal stem cells prevents arrested alveolar growth in neonatal lung injury in rats. Am J Respir Crit Care Med 2009, 180:1131-1142

14. Aslam M, Baveja R, Liang OD, Fernandez-Gonzalez A, Lee C, Mitsialis SA, Kourembanas S: Bone marrow stromal cells attenuate lung injury in a murine model of neonatal chronic lung disease. Am J Respir Crit Care Med 2009, 180:1122-1130

15. Chang YS, Oh W, Choi SJ, Sung DK, Kim SY, Choi EY, Kang S, Jin HJ, Yang YS, Park WS: Human umbilical cord blood-derived mesenchymal stem cells attenuate hyperoxia-induced lung injury in neonatal rats. Cell Transplant 2009, 18:869-886

16. Balasubramaniam V, Ryan SL, Seedorf GJ, Roth EV, Heumann TR, Yoder MC, Ingram DA, Hogan CJ, Markham NE, Abman SH: Bone marrow-derived angiogenic cells restore lung alveolar and vascular structure after neonatal hyperoxia in infant mice. Am J Physiol Lung Cell Mol Physiol 2010, 298:L315-L323

17. De Paepe ME, Mao Q, Ghanta S, Hovanesian V, Padbury JF: Alveolar epithelial cell therapy with human cord blood-derived hematopoietic progenitor cells. Am J Pathol 2011, 178:1329-1339

18. Mao Q, Chu S, Ghanta S, Padbury JF, De Paepe ME: Ex vivo expanded human cord blood-derived hematopoietic progenitor cells induce lung growth and alveolarization in injured newborn lungs. Respir Res 2013, 14:37

19. Borghesi A, Cova C, Gazzolo D, Stronati M: Stem cell therapy for neonatal diseases associated with preterm birth. J Clin Neonatol 2013, $2: 1-7$

20. Guan XJ, Song L, Han FF, Cui ZL, Chen X, Guo XJ, Xu WG: Mesenchymal stem cells protect cigarette smoke-damaged lung and pulmonary function partly via VEGF-VEGF receptors. J Cell Biochem 2013, 114:323-335

21. Cargnoni A, Gibelli L, Tosini A, Signoroni PB, Nassuato C, Arienti D, Lombardi G, Albertini A, Wengler GS, Parolini O: Transplantation of allogeneic and xenogeneic placenta-derived cells reduces bleomycininduced lung fibrosis. Cell Transplant 2009, 18:405-422

22. Moodley Y, Atienza D, Manuelpillai U, Samuel CS, Tchongue J, Ilancheran S, Boyd R, Trounson A: Human umbilical cord mesenchymal stem cells reduce fibrosis of bleomycin-induced lung injury. Am J Pathol 2009, 175:303-313

23. Lee SH, Jang AS, Kim YE, Cha JY, Kim TH, Jung S, Park SK, Lee YK, Won JH, Kim YH, Park CS: Modulation of cytokine and nitric oxide by mesenchymal stem cell transfer in lung injury/fibrosis. Respir Res 2010, 11:16

24. Gupta N, Su X, Popov B, Lee JW, Serikov V, Matthay MA: Intrapulmonary delivery of bone marrow-derived mesenchymal stem cells improves survival and attenuates endotoxin-induced acute lung injury in mice. J Immunol 2007, 179:1855-1863

25. Nemeth K, Leelahavanichkul A, Yuen PS, Mayer B, Parmelee A, Doi K, Robey PG, Leelahavanichkul K, Koller BH, Brown JM, Hu X, Jelinek I, Star RA, Mezey E: Bone marrow stromal cells attenuate sepsis via prostaglandin E(2)-dependent reprogramming of host macrophages to increase their interleukin-10 production. Nat Med 2009, 15:42-49

26. Mei SH, Haitsma JJ, Dos Santos CC, Deng Y, Lai PF, Slutsky AS, Liles WC, Stewart DJ: Mesenchymal stem cells reduce inflammation while enhancing bacterial clearance and improving survival in sepsis. Am J Respir Crit Care Med 2010, 182:1047-1057

27. Rojas M, Xu J, Woods CR, Mora AL, Spears W, Roman J, Brigham KL: Bone marrow-derived mesenchymal stem cells in repair of the injured lung. Am J Respir Cell Mol Biol 2005, 33:145-152

28. Shigemura N, Okumura M, Mizuno S, Imanishi Y, Nakamura T, Sawa Y: Autologous transplantation of adipose tissue-derived stromal cells ameliorates pulmonary emphysema. Am J Transplant 2006, 6: $2592-2600$

29. Zhen G, Liu H, Gu N, Zhang H, Xu Y, Zhang Z: Mesenchymal stem cells transplantation protects against rat pulmonary emphysema. Front Biosci 2008, 13:3415-3422

30. Islam MN, Das SR, Emin MT, Wei M, Sun L, Westphalen K, Rowlands DJ, Quadri SK, Bhattacharya S, Bhattacharya J: Mitochondrial transfer from bone-marrow-derived stromal cells to pulmonary alveoli protects against acute lung injury. Nat Med 2012, 18 : 759-765

31. Zhu YG, Feng XM, Abbott J, Fang XH, Hao Q, Monsel A, Qu JM, Matthay MA, Lee JW: Human mesenchymal stem cell microvesicles for treatment of Escherichia coli endotoxin-induced acute lung injury in mice. Stem Cells 2014, 32:116-125

32. Fung ME, Thebaud B: Stem cell-based therapy for neonatal lung disease: it is in the juice. Pediatr Res 2014, 75:2-7

33. Hansmann G, Fernandez-Gonzalez A, Aslam M, Vitali SH, Martin T, Mitsialis SA, Kourembanas S: Mesenchymal stem cell-mediated reversal of bronchopulmonary dysplasia and associated pulmonary hypertension. Pulm Circ 2012, 2:170-181

34. Chang YS, Choi SJ, Sung DK, Kim SY, Oh W, Yang YS, Park WS: Intratracheal transplantation of human umbilical cord blood-derived mesenchymal stem cells dose-dependently attenuates hyperoxiainduced lung injury in neonatal rats. Cell Transplant 2011, 20: $1843-1854$

35. Pierro M, Ionescu L, Montemurro T, Vadivel A, Weissmann G, Oudit G, Emery D, Bodiga S, Eaton F, Peault B, Mosca F, Lazzari L, Thebaud B: Short-term, long-term and paracrine effect of human umbilical cord-derived stem cells in lung injury prevention and repair in experimental bronchopulmonary dysplasia. Thorax 2013, 68: $475-484$

36. Ionescu L, Byrne RN, van Haaften T, Vadivel A, Alphonse RS, ReyParra GJ, Weissmann G, Hall A, Eaton F, Thebaud B: Stem cell conditioned medium improves acute lung injury in mice: in vivo evidence for stem cell paracrine action. Am J Physiol Lung Cell Mol Physiol 2012, 303:L967-L977

37. Antunes MA, Laffey JG, Pelosi P, Rocco PR: Mesenchymal stem cell trials for pulmonary diseases. J Cell Biochem 2014, 115: $1023-1032$

38. Chang YS, Ahn SY, Yoo HS, Sung SI, Choi SJ, Oh WI, Park WS: Mesenchymal stem cells for bronchopulmonary dysplasia: phase 1 dose-escalation clinical trial. J Pediatr 2014, 164:966-972.e6

39. Mao Q, Gundavarapu S, Patel C, Tsai A, Luks FI, De Paepe ME: The Fas system confers protection against alveolar disruption in hyperoxia-exposed newborn mice. Am J Respir Cell Mol Biol 2008, $39: 717-729$

40. Fritzell JA Jr, Mao Q, Gundavarapu S, Pasquariello T, Aliotta JM, Ayala A, Padbury JF, De Paepe ME: Fate and effects of adult bone marrow cells in lungs of normoxic and hyperoxic newborn mice. Am J Respir Cell Mol Biol 2009, 40:575-587

41. Crapo JD, Barry BE, Foscue HA, Shelburne J: Structural and biochemical changes in rat lungs occurring during exposures to lethal and adaptive doses of oxygen. Am Rev Respir Dis 1980, 122: 123-143

42. Dominici M, Le Blanc K, Mueller I, Slaper-Cortenbach I, Marini F, Krause D, Deans R, Keating A, Prockop D, Horwitz E: Minimal criteria for defining multipotent mesenchymal stromal cells: the International Society for Cellular Therapy position statement. Cytotherapy 2006, 8:315-317

43. Vanoirbeek JA, Rinaldi M, De Vooght V, Haenen S, Bobic S, GayanRamirez G, Hoet PH, Verbeken E, Decramer M, Nemery B, Janssens W: Noninvasive and invasive pulmonary function in mouse models of obstructive and restrictive respiratory diseases. Am J Respir Cell Mol Biol 2010, 42:96-104

44. Bates J: Lung Mechanics: An Inverse Modeling Approach. New York, Cambridge University Press, 2009 
45. De Paepe ME, Johnson BD, Papadakis K, Luks FI: Lung growth response after tracheal occlusion in fetal rabbits is gestational agedependent. Am J Respir Cell Mol Biol 1999, 21:65-76

46. De Paepe ME, Johnson BD, Papadakis K, Sueishi K, Luks FI: Temporal pattern of accelerated lung growth after tracheal occlusion in the fetal rabbit. Am J Pathol 1998, 152:179-190

47. Aherne WA, Dunnill, MS: The Estimation of Whole Organ Volume. Edited by Aherne WA, Dunnill MS. London, Edward Arnold Ltd, 1982, pp 10-18

48. De Paepe ME, Gundavarapu S, Tantravahi U, Pepperell JR, Haley SA, Luks FI, Mao Q: Fas-ligand-induced apoptosis of respiratory epithelial cells causes disruption of postcanalicular alveolar development. Am J Pathol 2008, 173:42-56

49. Yee M, Chess PR, McGrath-Morrow SA, Wang Z, Gelein R, Zhou R, Dean DA, Notter RH, O'Reilly MA: Neonatal oxygen adversely affects lung function in adult mice without altering surfactant composition or activity. Am J Physiol Lung Cell Mol Physiol 2009, 297:L641-L649

50. Shim YM, Paige M, Hanna H, Kim SH, Burdick MD, Strieter RM: Role of LTB(4) in the pathogenesis of elastase-induced murine pulmonary emphysema. Am J Physiol Lung Cell Mol Physiol 2010, 299: L749-L759

51. Shiner R, Steier J: Lung Function Tests. New York, Churchill Livingstone Elsevier, 2013
52. Pierro M, Thebaud B: Mesenchymal stem cells in chronic lung disease: culprit or savior? Am J Physiol Lung Cell Mol Physiol 2010, 298:L732-L734

53. Salazar KD, Lankford SM, Brody AR: Mesenchymal stem cells produce Wnt isoforms and TGF-beta1 that mediate proliferation and procollagen expression by lung fibroblasts. Am J Physiol Lung Cell Mol Physiol 2009, 297:L1002-L1011

54. Epperly MW, Guo H, Gretton JE, Greenberger JS: Bone marrow origin of myofibroblasts in irradiation pulmonary fibrosis. Am J Respir Cell Mol Biol 2003, 29:213-224

55. Sun Z, Wang C, Shi C, Sun F, Xu X, Qian W, Nie S, Han X: Activated Wnt signaling induces myofibroblast differentiation of mesenchymal stem cells, contributing to pulmonary fibrosis. Int J Mol Med 2014, 33:1097-1109

56. Tang N, Zhao Y, Feng R, Liu Y, Wang S, Wei W, Ding Q, An MS, Wen J, Li L: Lysophosphatidic acid accelerates lung fibrosis by inducing differentiation of mesenchymal stem cells into myofibroblasts. J Cell Mol Med 2014, 18:156-169

57. Weiss DJ: Concise review: current status of stem cells and regenerative medicine in lung biology and diseases. Stem Cells 2014, 32: $16-25$

58. Kassmer SH, Krause DS: Detection of bone marrow-derived lung epithelial cells. Exp Hematol 2010, 38:564-573 